\title{
Editorial
}

\section{Editorial: Increased Manuscript Submissions Prompt Journals to Make Hard Choices}

\author{
Seth S. Leopold MD
}

T $f$ the authorship of manuscripts is a business, one would have to say business is booming. Viewed from any vantage point, growth in scientific output appears enormous. One quantitative analysis suggested that the volume of scientific manuscript submissions to journals doubles every 15 years or so [7]. Another, focusing more on biomedical research, shared an analysis by Scopus showing a $3.5 \%$ compound annual growth rate [5], which makes a still-greater impression when presented visually (Fig. 1). In orthopaedics, the compound annual

The author certifies that he, or any members of his immediate family, has no commercial associations (eg, consultancies, stock ownership, equity interest, patent/licensing arrangements, etc) that might pose a conflict of interest in connection with the submitted article.

All ICMJE Conflict of Interest Forms for authors and Clinical Orthopaedics and Related Research ${ }^{\circledR}$ editors and board members are on file with the publication and can be viewed on request.

The opinions expressed are those of the writers, and do not reflect the opinion or policy of $C O R R^{\mathbb{R}}$ or the Association of Bone and Joint Surgeons ${ }^{\circledR}$.

S. S. Leopold MD (ه)

Clinical Orthopaedics and Related

Research, Philadelphia, PA 19103, USA

e-mail: sleopold@clinOrthop.org growth rate was even steeper, at $10.2 \%$ [8]. At Clinical Orthopaedics and Related Research ${ }^{\circledR}$, as a leading journal of the specialty, the numbers are even more dramatic: From 2012 to 2013 alone, manuscript submissions increased a whopping $29 \%$. That number went up again in 2014.

Happily, at least at $C O R R^{\circledR}$, it is not just quantity, but also quality. We are proud that in the last year-as in every year since we have been a journal-we have published papers that have changed how we think about important issues affecting our specialty $[2,6]$, about how we diagnose disease [4], and about how we treat our patients [3].

But the bounty must still be digested. Our specialty is not a large one, and the pool of available peer reviewers is only modest in size. Sixty-eight indexed orthopaedic journals (along with dozens or more of nonindexed titles) compete for these reviewers' services, which will be needed to evaluate the tens of thousands of manuscripts that musculoskeletal researchers will produce this year.

Many journals are taking steps to manage the increased volume of submissions. The two most common approaches are charging submission fees and more rigorous prescreening of manuscripts before sending them for peer review.

Several orthopaedic journals collect a fee at the time a manuscript is submitted, in order to defray the (considerable) overhead associated with contemporary publication, promotion, and dissemination of scientific work. Often, these journals make exceptions for authors whose means are limited or who are from less-affluent countries. Submission fees may cause authors of intermediate-to-lower quality work to think twice before submitting a manuscript, since they are nonrefundable in the event a manuscript is rejected. Journals employing this approach can decrease the volume of manuscripts they need to process. The goal is to have the authors selfscreen based on the desire not to spend money on a paper unlikely to be published, and so only send in the morerobust papers. The Journal of Bone and Joint Surgery has indicated that this was their experience since instituting submission fees [1]. Journals with stronger brands can succeed with a submission-fee approach; weaker journals may not. Questions have been raised about the fairness of this approach, in that journals collecting such fees benefit from the services of reviewers who perform the peer 
Fig. 1 A compound growth rate curve depicting the total growth in the number of scholarly papers published. The curve reflects a compound annual growth rate of approximately $3.5 \%$ [5]. The curve in orthopaedics is likely to be even steeper, with one analysis estimating that the compound annual growth rate for orthopaedic research is in excess of $10 \%$ [8]. Reprinted from Atherosclerosis, Volume 230. Number 2, Huggett $S$. Journal bibliometrics indicators and citation ethics: A discussion of current issues. 275-277. Copyright (October 2013), with permission from Elsevier.

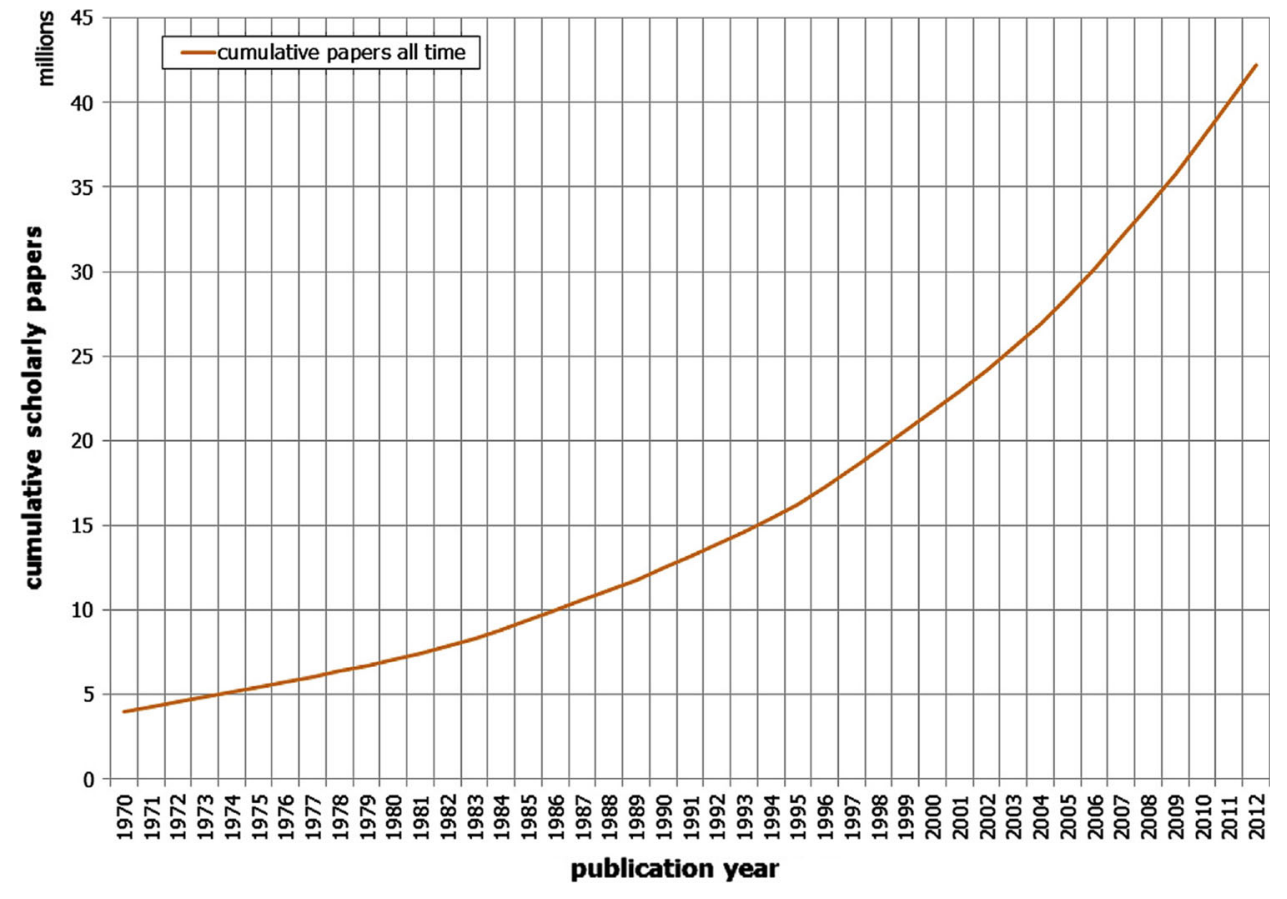

reviews, but these journals generally do not use these submission fees to remunerate reviewers for their contributions.

CORR ${ }^{\circledR}$ does not charge submission fees. Instead, we prescreen manuscripts to evaluate their suitability for peer review. Our Senior Editors evaluate every manuscript $C O R R^{\circledR}$ receives. Case reports typically are screened by one editor to evaluate for interest and educational value; clinical and laboratory research papers usually are screened by at least two Senior Editors for priority and methodological rigor. If both concur that a manuscript is unlikely to emerge from peer review with a recommendation to publish, the paper is returned promptly to the authors, saving those authors time. Otherwise, the work is sent out for formal peer review. Screening processes like this are employed by Nature, New England Journal of Medicine, Journal of the American Medical Association (JAMA), and numerous other highquality journals, and we believe that evaluating each work based on its merits rather than on its author's willingness (or ability) to pay maintains an important element of fairness in the process.
Even so, a pre-review screening process like this can rankle. I have not forgotten my first rejection from JAMA on a paper that the editor opted not to send for outside review, and I remember my initial reaction: "Can they just do that? Without even sending it out for peer review?" The answer is not only that they can, but that they must, and the same is true here at $\operatorname{CORR}^{\mathrm{R}}$. Another truth: My paper-like those screened by the Senior Editors at $C O R R^{\circledR}$ —in fact was reviewed, by one or more of the mostqualified evaluators at JAMA, and by 


\section{Editorial}

not sending that paper out for further review, when it had little or no chance of emerging from the process with a recommendation to publish, they saved me time.

The journal is not the sole beneficiary in when a pre-review screening process is used. As I noted, CORR ${ }^{\circledR}$ collects no manuscript-submission fees, which means there is no financial bar keeping any authors from submitting work to our journal. But the real winners here are the reader, and, further downstream, the patient. Our reviewer pool is finite in size, and these experts generously donate their time. Our job is to ensure that their time, as a valuable and limited resource, is spent on the thorough, unhurried evaluation of those papers most likely to make a difference. Keeping reviewers working on the most-promising papers that we receive makes it most likely that you-and your patients - will get the most out of each paper you read in $C O R R^{\circledR}$.
We are interested in your thoughts. Continue the conversation by sending an email to eic@clinorthop.org.

Acknowledgments I would like to thank Lee Beadling BS, Matthew B. Dobbs MD, and Montri D. Wongworawat MD, for their assistance in revising this editorial and for helping me to think about the issues behind it.

\section{References}

1. Anderson K. Publisher's note from Kent Anderson, CEO and publisher of $J B J S$. Available at: http://orthobuzz. jbjs.org/tag/orthopedic/. Accessed December 15, 2015.

2. Bohl DD, Basques BA, Golinvaux NS, Baumgaertner MR, Grauer JN. Nationwide inpatient sample and national surgical quality improvement program give different results in hip fracture studies. Clin Orthop Relat Res. 2014;472:1672-1680.

3. D'Apuzzo MR, Keller TC, Novicoff WM, Browne JA. CT pulmonary angiography after total joint arthroplasty: Overdiagnosis and iatrogenic harm? Clin Orthop Relat Res. 2013; 471:2737-2742.

4. Deirmengian C, Kardos K, Kilmartin P, Cameron A, Schiller K, Parvizi J. Diagnosing periprosthetic joint infection - Has the era of the biomarker arrived? Clin Orthop Relat Res. 2014;472:3254-3262.

5. Huggett S. Journal bibliometrics indicators and citation ethics: A discussion of current issues. Atherosclerosis. 2013; 230:275-277.

6. Koenig L, Dall TM, Gu Q, Saavoss J, Schafer MF. How does accounting for worker productivity affect the measured cost-effectiveness of lumbar discectomy? Clin Orthop Relat Res. 2014;472:1069-1079.

7. Larsen PO, von Ins M. The Rate of growth in scientific publication and the decline in coverage provided by the science citation index. Scientometrics. 2010;84:575-603.

8. Lee KM, Ryu MS, Chung CY, Choi IH, Kwon DG, Kim TW, Sung KH, Seo SG, Park MS. Characteristics and trends of orthopedic publications between 2000 and 2009. Clin Orthop Surg. 2011;3:225-229. 